\title{
HETEROSE E CAPACIDADE COMBINATÓRIA DE LINHAGENS DE TOMATEIRO RICAS EM ACILAÇÚCARES
}

\author{
Heterosis and combining ability of acylsugar-rich tomato lines
}

\author{
Gabriel Mascarenhas Maciel', Wilson Roberto Maluf ${ }^{2}$, Vanisse de Fátima Silva ${ }^{3}$, \\ Álvaro Carlos Gonçalves Neto ${ }^{3}$, Douglas Willian Nogueira ${ }^{4}$, Luiz Antônio Augusto Gomes ${ }^{2}$
}

\begin{abstract}
Resumo
Com o presente trabalho, objetivou-se estimar a capacidade combinatória de linhagens de tomate ricas em acilaçúcares (AA) quando cruzadas com linhagens com baixo teor de acilaçúcares e estudar a expressão da heterose nos híbridos obtidos. O experimento foi realizado no campo da HortiAgro Sementes Ltda, localizada em Ijaci-MG. O material genético foi constituído de seis híbridos experimentais em esquema de dialelo parcial, constituído de três genitores masculinos (grupo I, com altos teores de acilaçúcares) e dois genitores femininos (grupo II, com baixos teores). Foram avaliadas as características: massa média de fruto $\left(\mathrm{g}\right.$ fruto $\left.{ }^{-1}\right)$ e produção por hectare $\left(\mathrm{t} \mathrm{ha}^{-1}\right)$. As linhagens TOM-687 e TOM-688 (ricas em AA e resistentes a pragas) apresentaram estimativas positivas dos efeitos de capacidade geral de combinação, para massa média de frutos, e estimativas negativas, para produção, o que significa que elas contribuíram positivamente para aumento no tamanho do fruto, mas reduziram a produtividade dos híbridos. Já a linhagem TOM689, ao contrário das duas anteriores, contribuiu para reduzir o tamanho do fruto, mas contribuiu para aumentar a produtividade dos híbridos. Os híbridos obtidos do cruzamento de linhagens com altos teores de acilaçúcares mostraram-se competitivas quando comparadas a híbridos comerciais encontrados no mercado. As melhores combinações híbridos foram obtidas quando as linhas com altos teores de acilaçúcares foram cruzadas com a linhagem elite TOM-684.
\end{abstract}

Termos para indexação: Lycopersicon pennellii, vigor híbrido, aleloquímicos.

\begin{abstract}
The objective of this work was to assess heterosis and combining ability of tomato lines with high acylsugar (AS) content (group I) and lines with low AS (group II) used to produce AS-rich tomato hybrids. The trial was carried out at the seed production station of the HortiAgro Sementes Ltda., at Ijaci-MG. The genetic material consisted of six experimental hybrids obtained from crosses between three male parents with high AS (group I) and two female parents with low AS (group II). Average fruit weight $\left(\mathrm{g}_{\text {fruit }}{ }^{-1}\right)$ and total yield $\left(\mathrm{t} \mathrm{ha}^{-1}\right)$ were the traits assessed. The AS-rich pest-resistant lines TOM-687 and TOM-688 showed positive estimates of general combining ability for average fruit mass and negative for yield, increasing fruit size, and reducing the yield of the hybrids. Unlike the two previous lines, TOM-689 presented negative estimates for fruit mass and positive for fruit yield. The data showed that it is feasible to get competitive hybrids from lines with AS sugar content. The best hybrids were produced when these lines were crossed with TOM-684.
\end{abstract}

Index terms: Lycopersicon pennellii, hybrid vigor, allelochemicals.

(Recebido em 30 de janeiro de 2010 e aprovado em 6 de julho de 2010)

\section{INTRODUÇÃO}

Nos programas de melhoramento genético do tomateiro, os melhoristas visam à obtenção de híbridos com resistência múltipla às principais doenças, principalmente aquelas controladas por genes maiores dominantes, aliando sobretudo à produtividade e a qualidade de frutos. Para isso é necessário dispor de linhagens melhoradas que permitem alcançar tais objetivos mediante sua utilização como genitoras. Linhagens com resistência múltipla a doenças são relativamente frequentes em bancos de germoplasma de programas de melhoramento, o mesmo não acontece com linhagens resistentes a pragas. Recentemente, tornaram-se disponíveis algumas linhagens de tomateiro que aliam boas características comerciais com altos teores foliares de acilaçúcares (AA) (Maciel, 2008), aleloquímicos associados à resistência a uma gama de pragas da cultura (Pereira et al., 2008; Resende et al., 2006, 2008, 2009; Silva et al., 2008).

Essas linhagens melhoradas foram obtidas a partir do cruzamento inicial entre o tomateiro comercial Solanum lycopersicum (= Lycopersicon esculentum P. Miller) e a espécie selvagem, rica em acilaçúcares, Solanum pennellii [= L. pennellii (Correll) D'Arcy], que possui resistência

1Universidade Federal de Lavras/UFLA - Cx. P. 3037 - 37200-000 - Lavras, MG - gabrielmascarenhasmaciel@yahoo.com.br

${ }^{2}$ Universidade Federal de Lavras/UFLA - Departamento de Agricultura/DAG - Lavras, MG

${ }^{3}$ Universidade Federal de Lavras/UFLA - Lavras, MG

${ }^{4}$ Universidade Federal de Lavras/UFLA - Departamento de Biologia/DBI - Lavras, MG 
documentada a um grande número de artrópodos-praga (Resende et al., 2006, 2008). Gonçalves et al. (2007) indicaram que altos teores de AA se devem à ação de um alelo recessivo, com dominância incompleta no sentido de baixos teores. Plantas com altos teores de AA foram resistentes à mosca branca Bemisia argentifolii Bellows \& Perring (Homoptera: Aleyrodidae) (Liledl et al., 1995; Maciel, 2008; Resende et al., 2009) e aos ácaros Tetranychus spp (Saeidi et al., 2007; Maciel, 2008; Pereira et al., 2008; Resende et al., 2008) e tiveram confirmada sua resistência à traça Tuta absoluta (Meyrick, 1917) (Lepidóptera: Gelechiidae) (Resende et al., 2006) em gerações segregantes. Tal fato se reveste de especial importância, pois embora a resistência a pragas em tomateiro mediada por AA seja bem documentada (Goffreda et al., 1989; Juvik et al., 1994; Liedl et al., 1995; Gonçalves et al., 2007; Resende et al., 2006, 2008; Saeidi et al., 2007; Maciel, 2008), ainda não estão disponíveis, no mercado, tomateiros comerciais com níveis satisfatórios de resistência.

Híbridos com amplo espectro de resistência a pragas foram obtidos em estudos realizados por Maciel (2008), com base em três linhagens-elite ricas em AA pertencentes ao banco de germoplasma da empresa HortiAgro Sementes Ltda./Ijaci-MG. Híbridos com teores intermediários de AA, obtidos entre linhagens com altos teores e linhagens com baixos teores, possuem níveis satisfatórios de resistência a Tretranychus urticae Koch (Acari: Tetranychidae) e principalmente a $T$. absoluta e B. argentifolii. Apesar da eficiência dos híbridos com teores intermediários de AA em conferir resistência a pragas, pouco se sabe a respeito da capacidade combinatória destas linhagens-elite e de seu potencial para gerar híbridos competitivos comercialmente.

Este trabalho foi realizado com o objetivo de inferir sobre a capacidade combinatória de linhagens-elite com altos teores de AA, disponíveis na HortiAgro Sementes Ltda., e linhagens de baixos teores de AA, para a obtenção de híbridos de tomateiro com teores intermediários de AA com alta performance agronômica. O trabalho também visa a estudar a expressão da heterose e de suas componentes nos híbridos obtidos.

\section{MATERIAL E MÉTODOS}

O experimento foi instalado no setor de produção de sementes da HortiAgro Sementes Ltda, localizada no município de Ijaci, MG (2114'16” de latitude Sul, 4508'00' de longitude Oeste, altitude de $920 \mathrm{~m}$ ), no período de 20/02/2007 a 15/08/2007. A temperatura e precipitação média em todo o período de avaliação foram de $17,1^{\circ} \mathrm{C}$ e $66,0 \mathrm{~mm}$, respectivamente.
Os genótipos utilizados estão descritos na Tabela 1. As linhagens descritas, com exceção da linhagem TOM-684, foram obtidas a partir do cruzamento interespecífico inicial entre $S$. lycopersicum (TOM-584, linhagem pré-comercial com boas características agronômicas possuindo baixo teor de AA) x $S$. pennellii 'LA-716', com alto teor de AA. O cruzamento interespecífico foi seguido de três ciclos de retrocruzamento-autofecundação-seleção para teores de acilaçúcares e, após sucessivas autofecundações adicionais, foram obtidas três linhagens com altos teores foliares de AA (TOM-687, TOM-688, TOM-689) e uma linhagem com baixos teores foliares de AA (TOM-690). TOM-687, TOM-688, TOM-689 possuem plantas de crescimento indeterminado e amplo espectro de resistência a pragas, particularmente Tetranychus urticae, Tuta absoluta e Bemisia argentifolii (Maciel, 2008), enquanto TOM-690, com genealogia semelhante, foi selecionada para baixos teores de AA e é, presumivelmente, suscetível a estas pragas. A linhagem-elite TOM-684, juntamente com TOM-687, TOM-688, TOM-689 e TOM-690, foi utilizada para obtenção de 6 híbridos experimentais com teores foliares intermediários de AA [(F1 (TOM-684 x TOM-687), F1 (TOM-684 x TOM-688), F1 (TOM-684 x TOM-689), F1 (TOM-690 x TOM-687), F1 (TOM-690 x TOM-688) e F1 (TOM-690 x TOM-689)], um híbrido com altos teores foliares de AA F1 [(TOM-687 x TOM-689)], e um híbrido experimental com baixo teor de AA [F1 (TOM-684 x TOM-690)]. Os treze genótipos (cinco linhagens, oito híbridos experimentais) foram avaliados para características agronômicas, juntamente com três testemunhas comerciais (Bravo $\mathrm{F}_{1}$, Bônus e Débora Max).

Todos os 16 genótipos (Tabela 1) foram semeados em bandejas de isopor de 128 células no dia 20/02/2007, utilizando como substrato o produto comercial Plantmax ${ }^{\circledR}$. As plantas foram transplantadas para o campo no estádio de 4 a 6 folhas definitivas no dia 15/03/2007. Foi utilizado o espaçamento de $1,00 \mathrm{~m} \times 0,50 \mathrm{~m}$, em tutoramento com haste simples, totalizando 20.000 plantas por hectare. Cada parcela foi constituída por 12 plantas distribuídas em 6 metros lineares. Foi utilizada bordadura delimitando toda área experimental de campo. A condução do experimento foi de acordo com as recomendações de cultivo comercial de tomate em nível de campo (Alvarenga, 2004), fazendose irrigações (por gotejamento), adubações, pulverizações, capinas, desbrotas e amarrios. As plantas foram tutoradas com uma haste em linhas duplas.

Foram realizadas 16 colheitas com intervalos de 5 dias entre cada colheita. A primeira colheita foi feita aos 85 dias após o transplantio (08/06/2007). 
Tabela1 - Descrição dos genótipos de tomateiro utilizados no ensaio: Departamento de Agricultura, Lavras, MG, 2007.

\begin{tabular}{ll}
\hline Genótipos/Tratamentos & \multicolumn{1}{c}{ Descrição } \\
\hline TOM-687 = & Linhagem pré-comercial com alto teor de acilaçúcares.(A.A) \\
TOM-688=2 & Linhagem pré-comercial com alto teor de acilaçúcares.(A.A) \\
TOM-689=3 & Linhagem pré-comercial com alto teor de acilaçúcares.(A.A) \\
TOM-690=1 & Linhagem comercial com baixo teor de acilaçúcares (A.A) \\
TOM-684=2 & Linhagem pré-comercial com baixo teor de acilaçúcares. (A.A) \\
F1 (TOM-684 x TOM-687) & Híbrido experimental F1 (Baixo teor de A.A. x Alto teor de A.A) \\
F1 (TOM-684 x TOM-688) & Híbrido experimental F1 (Baixo teor de A.A. x Alto teor de A.A) \\
F1 (TOM-684 x TOM-689) & Híbrido experimental F1 (Baixo teor de A.A. x Alto teor de A.A) \\
F1 (TOM-690 x TOM-687) & Híbrido experimental F1 (Baixo teor de A.A. x Alto teor de A.A) \\
F1 (TOM-690 x TOM-688) & Híbrido experimental F1 (Baixo teor de A.A. x Alto teor de A.A) \\
F1 (TOM-690 x TOM-689) & Híbrido experimental F1 (Baixo teor de A.A. x Alto teor de A.A) \\
F1 (TOM-687 x TOM-689) & Híbrido experimental F1 (Alto teor de A.A. x Alto teor de A.A) \\
F1 (TOM-684 x TOM-690) & Híbrido experimental F1 (Baixo teor de A.A. x Baixo teor de A.A) \\
BRAVO F1 & Híbrido comercial (Testemunha), Baixo teor de A.A. \\
BONUS F1 & Híbrido comercial (Testemunha), Baixo teor de A.A. \\
DEBORA MAX & Híbrido comercial (Testemunha), Baixo teor de A.A.
\end{tabular}

Linhagens utilizadas como parentais masculinos pertencentes ao grupo I: 1 = TOM-687, 2= TOM-688, 3= TOM-689 e Linhagens utilizadas como parentais femininos pertencentes ao grupo II: $1^{`}=$ TOM-690, $2^{`}=$ TOM- 684 .

Avaliaram-se as seguintes características: massa média de fruto $\left(\mathrm{g}_{\text {fruto }}{ }^{-1}\right)$ e produção por hectare $\left(\mathrm{t} \mathrm{ha}^{-1}\right)$. Foi utilizado o delineamento em blocos casualisados contendo três repetições sendo as médias comparadas pelo teste de Tukey a $5 \%$ de probabilidade.

Os genótipos avaliados foram submetidos a análise dialélica para as características avaliadas. O material genético utilizado para análise dialélica foi constituído de três genitores masculinos (fonte de pólen) (1 = TOM-687; 2 = TOM-688; 3 = TOM-689) com altos teores foliares de AA (Grupo I) e dois genitores femininos (1'=TOM-690; 2'=TOM-684) com baixos teores foliares de AA (Grupo II).

Os seis híbridos experimentais obtidos pela combinação das linhagens do grupo I e grupo II (todos com teores foliares intermediários de AA) e seus respectivos genitores foram incluídos na análise dialélica segundo o modelo de cruzamento dialélico proposto por Miranda Filho \& Geraldi (1984).

Procedeu-se, primeiramente, à análise de variância para cada um dos caracteres avaliados para o delineamento em blocos casualizados, utilizando-se o seguinte modelo estatístico: $\mathrm{Y}_{\mathrm{ij}}=\mu+\mathrm{b}_{\mathrm{j}}+\mathrm{t}_{\mathrm{i}}+\mathrm{e}_{\mathrm{ij}}$. \& Geraldi (1984):
$\mathrm{Y}_{\mathrm{ij}}=\mu+\alpha d+1 / 2\left(v_{i}+v_{j}\right)+\theta\left(h m+h_{i}+h_{\mathrm{j}}+s_{i j}\right)+e_{i j}$

em que:

$\mu=$ média das linhagens genitoras;

$d=$ diferença entre as médias dos dois grupos de variedades 1 e 2 ;

$v_{i}$ e $v_{j}=$ efeitos varietais relativos aos grupos 1 e 2, respectivamente;

$\mathrm{hm}=$ heterose média de todos os cruzamentos;

$h_{i}$ e $h_{j}=$ efeitos de heterose varietal relativos aos grupos 1 e 2, respectivamente;

$s i j=$ heterose específica do cruzamento entre as variedades ou populações $i$ e $j$;

$\mathrm{e}_{\mathrm{ij}}$ é o erro experimental médio associado às médias observadas $Y i j$.

As variáveis indicadoras $\alpha$ e $\theta$ assumem os valores: $\alpha=0$ e $\theta=1$, para os híbridos; $\alpha=1$ e $\theta=0$, para as variedades parentais do grupo $1, \operatorname{com} Y_{i j}=Y_{i i}$; ou $\alpha=-1 \mathrm{e}$ $\theta=0$, para as variedades do grupo $2, \operatorname{com} Y_{i j}=Y_{j j}$. Ademais, foram assumidas as seguintes restrições paramétricas:

$\sum_{\mathrm{i}} \mathrm{v}_{\mathrm{i}}=\sum_{\mathrm{j}} \mathrm{v}_{\mathrm{j}}=\sum_{\mathrm{i}} \mathrm{h}_{\mathrm{i}}=\sum_{\mathrm{j}} \mathrm{h}_{\mathrm{j}}=0$ e $\sum_{\mathrm{i}} \mathrm{s}_{\mathrm{ij}}=\sum_{\mathrm{j}} \mathrm{s}_{\mathrm{ij}}=0$ 
Nesse modelo, a heterose total (h) é decomposta em heterose média ( $\mathrm{hm}$ ), heterose das linhagens do grupo I $(h i)$, heterose das linhagens do grupo II $(h j)$ e heterose específica (sij).

Estimou-se também a capacidade geral de combinação (CGC) em cada genitor ( $g i$ e $g j$ ), correspondente ao método IV de Griffing (1956) para as variáveis produção $\left(\mathrm{t} \mathrm{ha}^{-1}\right) \mathrm{e}$ massa média de frutos $\left(\mathrm{g}_{\text {fruto }}{ }^{-1}\right)$, utilizando-se as expressões: $g i=1 / 2\left(v_{i}\right)+h_{i}$ e $g j=1 / 2\left(v_{j}\right)+h_{j}$.

\section{RESULTADOS E DISCUSSÃO}

Os híbridos experimentais F1 (TOM-684 x TOM687), F1 (TOM-684 x TOM-688) e F1 (TOM-684 x TOM689) não se diferenciaram das testemunhas comerciais com relação à massa média de frutos $\left(\mathrm{g}_{\text {fruto }}{ }^{-1}\right)$ e produção por hectare ( $\mathrm{t} \mathrm{ha}^{-1}$ ) (Tabela 2), o que mostra a possibilidade da obtenção de híbridos competitivos comercialmente e resistentes a pragas.

Tabela 2 - Comparação das médias para peso médio do fruto $\left(\mathrm{g}\right.$ fruto $\left.{ }^{-1}\right)$ e produção por hectare $\left(\mathrm{t} \mathrm{ha}^{-1}\right) \mathrm{em}$ genótipos de tomateiro: Departamento de Agricultura, Lavras, MG, 2007.

\begin{tabular}{lll}
\hline \multicolumn{1}{c}{ Genótipos } & \multicolumn{1}{c}{$\mathrm{g} \mathrm{fruto}^{-1}$} & \multicolumn{1}{c}{$\mathrm{t} \mathrm{ha}^{-1}$} \\
\hline TOM-687 & $134,3 \mathrm{AB}^{(1)}$ & $36,73 \mathrm{D}$ \\
TOM-688 & $131,6 \mathrm{AB}$ & $40,00 \mathrm{D}$ \\
TOM-689 & $108,3 \mathrm{~B}$ & $38,13 \mathrm{D}$ \\
TOM-690 & $139,3 \mathrm{AB}$ & $35,86 \mathrm{D}$ \\
TOM-684 & $149,3 \mathrm{~A}$ & $67,64 \mathrm{AB}$ \\
F1 (TOM-684 x TOM-687) & $154,3 \mathrm{~A}$ & $67,53 \mathrm{AB}$ \\
F1 (TOM-684 x TOM-688) & $154,3 \mathrm{~A}$ & $68,53 \mathrm{AB}$ \\
F1 (TOM-684 x TOM-689) & $144,3 \mathrm{~A}$ & $64,13 \mathrm{AB}$ \\
F1 (TOM-690 x TOM-687) & $143,6 \mathrm{~A}$ & $40,60 \mathrm{CD}$ \\
F1 (TOM-690 x TOM-688) & $139,0 \mathrm{AB}$ & $41,66 \mathrm{CD}$ \\
F1 (TOM-690 x TOM-689) & $130,3 \mathrm{AB}$ & $52,73 \mathrm{ABCD}$ \\
F1 (TOM-687 x TOM-689) & $126,3 \mathrm{AB}$ & $47,77 \mathrm{BCD}$ \\
F1 (TOM-684 x TOM-690) & $158,0 \mathrm{~A}$ & $62,66 \mathrm{ABC}$ \\
BRAVO F1 & $142,3 \mathrm{~A}$ & $70,44 \mathrm{~A}$ \\
BONUS F1 & $135,3 \mathrm{AB}$ & $74,40 \mathrm{~A}$ \\
DEBORA MAX & $136,0 \mathrm{AB}$ & $74,20 \mathrm{~A}$ \\
\hline Média Geral & 145,31 & 55,19 \\
\hline C.V (\%) & 7,55 & 13,23 \\
\hline
\end{tabular}

${ }^{1}$ médias seguidas da mesma letra, nas colunas, não diferem entre si pelo teste de Tukey $(\mathrm{P}<0,05)$.
As linhagens com alto teor de AA TOM-687 e TOM688 não diferem significativamente das testemunhas comerciais para peso médio dos frutos, demonstrando que, além da presença de alto teor de AA, possuem uma característica agronômica de grande importância em nível comercial (tamanho comercial de frutos). Com exceção da linhagem TOM-684, todas as outras linhagens genitoras apresentaram menores produtividades do que as testemunhas comerciais (Tabela 2). A menor produtividade das linhagens ricas em acilaçúcares TOM-687, TOM-688 e TOM-689 não refletiu, no entanto, em menor produtividade de seus híbridos, principalmente considerando os cruzamentos com a linhagem-elite TOM684 (Tabela 2). Os híbridos F1 (TOM-684 x TOM-687), F1 (TOM-684 x TOM-688) F1 (TOM-684 x TOM-689), com teores intermediários de AA, são, portanto, potencialmente comercializáveis, pois possuem produtividade e tamanho de frutos comparáveis aos das testemunhas comerciais. Com os resultados apresentados pelos híbridos com teores intermediários de AA e a resistência a pragas comprovada por Maciel (2008), fica evidente o potencial das linhagens com alto teor de AA para a obtenção de híbridos de tomateiro resistentes a pragas e com potencial de comercialização (Tabela 2).

Os quadrados médios da análise de variância para massa média de frutos $\left(\mathrm{g}_{\text {fruto }}{ }^{-1}\right)$ e produção por hectare $\left(\mathrm{t} \mathrm{ha}^{-1}\right)$, obtidos pelo ajuste do modelo dialélico parcial de Miranda Filho \& Geraldi (1984), são apresentados na Tabela 3, observando-se uma maior variação entre as médias da massa dos frutos $\left(\mathrm{g}_{\text {fruto }}{ }^{-1}\right)$ no grupo I do que no grupo II, indicada pelas estimativas dos quadrados médios dentro de cada grupo. $\mathrm{O}$ inverso ocorreu para produção $\left(\mathrm{t} \mathrm{ha}^{-1}\right)$, em que as linhagens do grupo II apresentaram maior variação em relação às linhagens do grupo I. Os efeitos varietais $\left(v_{i}, v_{j}\right)$ foram significativos para massa média de frutos; já para produção ( $\mathrm{t} \mathrm{ha}^{-1}$ ), apenas os efeitos varietais do grupo II $\left(v_{j}\right)$ foram significativos.

As significâncias dos valores de heterose média $h m$, para ambas as características estudadas (Tabela 3), refletem a superioridade das médias dos híbridos experimentais em relação à média dos genitores (Tabela 2 e 3 ). As heteroses de grupos ( $h i, h j)$ e a heterose específica ( $s i j$ ) não foram significativas nem para massa média de frutos nem para produtividade, indicando pequena divergência genética intragrupos entre as linhagens. A não significância dos valores de heterose específica reflete a maior importância da variância aditiva na expressão de ambas as características estudadas. Sendo então possível obter ganho genético para esses caracteres avaliando os parentais per se. 
Tabela 3 - Analise de variância para massa média dos frutos $\left(\mathrm{g}_{\text {fruto }}{ }^{-1}\right)$ e produção total $\left(\mathrm{t} \mathrm{ha}{ }^{-1}\right)$ em cruzamento dialélico parcial entre linhagens de tomateiro: Departamento de Agricultura, Lavras, MG, 2007.

\begin{tabular}{lccc}
\hline \multirow{2}{*}{ FV } & \multicolumn{2}{c}{ QM } \\
\cline { 2 - 4 } Bloco & GL & Massa Média de frutos $\left(\mathrm{g}\right.$ fruto $\left.{ }^{-1}\right)$ & $\mathrm{t} \mathrm{ha}^{-1}$ \\
\cline { 2 - 4 } Análise Dialélica & 2 & $1,351^{* *}$ & $657,55^{* *}$ \\
$\quad$ Entre tratamentos do Dialelo & 10 & & \\
$\quad$ Linhagens do Grupo I vs Grupo II & 1 & $0,51^{* *}$ & $582,76^{* *}$ \\
Entre linhagens do Grupo I & 2 & $1,71^{* *}$ & $928,76^{* *}$ \\
Entre linhagens do Grupo II & 1 & $0,90^{* *}$ & $17,97^{\mathrm{ns}}$ \\
Heterose & 6 & $0,68^{*}$ & $3552,12^{* *}$ \\
Heterose Média & 1 & $0,15^{\mathrm{ns}}$ & $218,46^{* *}$ \\
Heterose entre Linhagens do Grupo I & 2 & $0,82^{*}$ & $940,33^{* *}$ \\
Heterose entre Linhagens do Grupo II & 1 & $0,00^{\mathrm{ns}}$ & $21,32^{\mathrm{ns}}$ \\
Heterose Específica & 2 & $0,25^{\mathrm{ns}}$ & $87,70^{\mathrm{ns}}$ \\
\hline Erro Médio & 20 & $0,10^{\mathrm{ns}}$ & $120,05^{\mathrm{ns}}$ \\
\hline CV (\%) & & 0,12 & 52,53 \\
Média Geral & & 7,55 & 13,34 \\
\hline
\end{tabular}

$\mathrm{ns}, * *, *$ : não significativo e significativo, a $1 \%$ e $5 \%$ de probabilidade, pelo teste de $\mathrm{F}$, respectivamente.

Os efeitos varietais do grupo I $\left(v_{i}\right)$ tiveram uma participação mais expressiva na massa média de frutos, comparativamente às linhagens do grupo II $\left(v_{j}\right)$, refletindo uma maior divergência genética relativa entre os genitores do primeiro grupo do que entre os do segundo. Dada a relativamente pequena importância dos efeitos de heterose varietal $\left(h_{i}, h_{j}\right)$, os valores de $g_{i} / g_{j}$ refletem principalmente os valores de $v_{i} / v_{j}:$ no grupo I, as estimativas de $v_{i}$ variaram de $-16,7 \mathrm{~g}$ a $9,3 \mathrm{~g}$, com amplitude de $26,0 \mathrm{~g}$, o que representa $19,35 \%$ do valor da média geral $(\mu=134,33 \mathrm{~g})$. Dentro do grupo II, a amplitude observada para os $v_{j}$ foi de $10,0 \mathrm{~g}$ e representa apenas $7,44 \%$ da variação média total (Tabela 4).

As maiores estimativas dos efeitos varietais para massa média de frutos foram exibidas pelas linhagens 1 (TOM-687) e 2 (TOM-688), com valores de 9,3 g e 7,4 g, respectivamente. Esses valores resultaram também nas maiores estimativas da capacidade geral de combinação (CGC) para esses mesmos genitores [4,95 e 2,6 g, respectivamente (Tabela 5)].

Os efeitos da heterose específica $\left(\mathrm{s}_{\mathrm{ij}}\right)$ para massa média de frutos variaram de $-1,0 \mathrm{~g}$ a $1,0 \mathrm{~g}$, valores cuja amplitude de 2,0 $\mathrm{g}$ representa apenas 1,48\% da média, valor esse que reflete a pouca importância dos efeitos $s_{i j}$ na expressão do caráter (Tabela 4).

As estimativas dos efeitos varietais $\left(v_{i}\right)$ apresentados para produção por hectare $\left(t \mathrm{tha}^{-1}\right)$ entre as linhagens do grupo I variaram de $-1,56$ a $1,71 \mathrm{t} \mathrm{ha}^{-1}$ [amplitude total de $3,27 \mathrm{t} \mathrm{ha}^{-1}$, (valor pouco relevante comparativamente a $\left.\mu=45,023 \mathrm{t} \mathrm{ha}^{-1}\right)$ ] (Tabelas 4), de modo que todas as linhagens componentes do grupo 1 se comportaram semelhantemente quanto à produtividade. Entre as linhagens do grupo II, as estimativas dos efeitos varietais $\left(v_{i}\right)$ variaram de $-15,89$ a $15,89 \mathrm{tha}^{-1}$, com amplitude total de $31,78 \mathrm{t} \mathrm{ha}^{-1}$ [valor considerável quando comparado à média geral $\left(\mu=45,023 \mathrm{t} \mathrm{ha}^{-1}\right)$ ] (Tabela 4$)$, indicando uma nítida superioridade da linhagem elite TOM-684 $\left(\mathrm{v}_{2}=15,89\right.$ ton $\left.\mathrm{ha}^{-1}\right)$, tanto na sua produtividade per se quanto na dos híbridos dos quais é genitora $\left(\mathrm{g}_{2}=10,86\right.$ ton ha ${ }^{-1}$ (Tabelas 4 e 5).

A heterose específica $\left(s_{i j}\right)$ para produtividade foi não significativo (Tabela 3), e com magnitude baixa em relação à média total (Tabela 4), indicando a predominância de efeitos aditivos na expressão do caráter. Esses resultados contrastam com os de Melo et al. (1988) e Amaral Júnior et al. (1999), que observaram a predominância dos efeitos não-aditivos na expressão da produção por hectare em tomateiro. 
Tabela 4 - Estimativas dos efeitos da média dos grupos varietais, desvio entre grupo e heterose média $(\mu, d$ e $h m$, respectivamente), de variedades $\left(v_{i}\right.$ e $\left.v_{j}\right)$, de heterose varietal $\left(h_{i}\right.$ e $\left.h\right)$ e da heterose específica $\left(S_{i j}\right)$, para as variáveis produção $\left(\mathrm{t}^{i} \mathrm{~h}^{-1}\right)$ e massa média de frutos $\left(\mathrm{g}\right.$ fruto $\left.^{-1}\right)$ em genótipos de tomateiro: Departamento de Agricultura, Lavras, MG, 2007.

\begin{tabular}{ccc}
\hline Parâmetros & Massa média de frutos & Produção \\
\cline { 2 - 3 }$\mu$ & $\left(\mathrm{g} \mathrm{fruto}^{-1}\right)$ & $\left(\mathrm{t} \mathrm{ha}^{-1}\right)$ \\
$\mathrm{D}$ & 134,33 & 45,023 \\
$\mathrm{v}_{1}$ & $-9,66$ & $-6,736$ \\
$\mathrm{v}_{2}$ & 9,30 & $-1,560$ \\
$\mathrm{v}_{3}$ & 7,40 & 1,710 \\
$\mathrm{v}_{1}{ }^{\prime}$ & $-16,70$ & $-0,150$ \\
$\mathrm{v}_{2}$, & $-5,00$ & $-15,890$ \\
$\mathrm{Hm}^{\prime}$ & 5,00 & 15,890 \\
$\mathrm{~h}_{1}$ & 10,17 & 10,840 \\
$\mathrm{~h}_{2}$ & 0,30 & $-1,020$ \\
$\mathrm{~h}_{3}$ & $-1,10$ & $-1,620$ \\
$\mathrm{~h}_{1}$, & 0,80 & 2,640 \\
$\mathrm{~h}_{2}$, & $-4,30$ & $-2,920$ \\
$\mathrm{~S}_{1^{\prime} 1}$ & 4,30 & 2,920 \\
$\mathrm{~S}_{2^{\prime} 1}$ & 1,00 & $-2,600$ \\
$\mathrm{~S}_{1^{\prime} 2}$ & $-1,00$ & 2,600 \\
$\mathrm{~S}_{2}{ }^{\prime} 2$ & $-1,00$ & $-2,565$ \\
$\mathrm{~S}_{1^{\prime} 3}$ & 1,00 & 2,565 \\
$\mathrm{~S}_{2}{ }^{\prime} 3$ & 0,00 & 5,165 \\
\hline & 0,00 & $-5,165$ \\
\hline
\end{tabular}

Linhagens utilizadas como parentais masculinos pertencentes ao grupo I: 1 = TOM-687, 2= TOM-688, 3= TOM-689 e Linhagens utilizadas como parentais femininos pertencentes ao grupo II: $1^{`}=$ TOM-690, 2‘= TOM-684.

As combinações híbridas 2'x1 [ $\mathrm{F}_{1}(\mathrm{TOM}-684 \mathrm{x}$ TOM-687)], 2' x 2 [F (TOM-684 x TOM-688)] e 2'x3 [F $\mathrm{F}_{1}$ (TOM-684 x TOM-689)] apresentaram as maiores estimativas de $\mathrm{g}_{\mathrm{i}}+\mathrm{g}_{\mathrm{j}}+\mathrm{s}_{\mathrm{ij}}$, tanto para massa média de frutos $\left(\mathrm{g}_{\mathrm{i}}+\mathrm{g}_{\mathrm{j}}+\mathrm{s}_{\mathrm{ij}}=10,75 ; 10,40 \mathrm{e}-0,75 \mathrm{~g}\right.$ respectivamente) quanto para produção $\left(\mathrm{g}_{\mathrm{i}}+\mathrm{g}_{\mathrm{j}}+\mathrm{s}_{\mathrm{ij}}=11,660 ; 12,665\right.$ e $8,255 \mathrm{t} \mathrm{ha}^{-1}$ respectivamente), tendo sido, dessa maneira, os que mais se destacaram para ambas as características analisadas.

As linhagens TOM-687 e TOM-688 (ricas em A.A), presumivelmente resistentes a pragas (Maciel, 2008), apresentaram maiores estimativas dos efeitos de capacidade geral de combinação para massa média de frutos relativamente a TOM-689 e não diferiram dessa última quanto à capacidade combinatória para produção.

Também quando foram utilizadas como genitoras, principalmente em combinação com a linhagem elite TOM684 , foram obtidos os melhores híbridos, comparáveis às testemunhas comerciais.

Tabela 5 - Capacidade geral de combinação (CGC) segundo o método IV de Griffing [ $g i=1 / 2\left(v_{i}\right)+h_{i}$ e $g j=1 / 2\left(v_{j}\right)+h_{j}$ ] para as variáveis produção $\left(\mathrm{t} \mathrm{ha}^{-1}\right)$ e massa média de frutos $\left(\mathrm{g}\right.$ fruto $\left.^{-1}\right)$ em genótipos de tomateiro: Departamento de Agricultura, Lavras, MG, 2007.

\begin{tabular}{ccc}
\hline \multirow{2}{*}{ Parâmetros } & Massa média de frutos & Produção \\
\cline { 2 - 3 } & $\left(\mathrm{g} \mathrm{fruto}^{-1}\right)$ & $\left(\mathrm{t} \mathrm{ha}^{-1}\right)$ \\
\cline { 2 - 3 } $\mathrm{g}_{1}$ & 4,95 & $-1,800$ \\
$\mathrm{~g}_{2}$ & 2,60 & $-0,760$ \\
$\mathrm{~g}_{3}$ & $-7,55$ & 2,560 \\
$\mathrm{~g}_{1}$, & $-6,80$ & $-10,860$ \\
$\mathrm{~g}_{2}$, & 6,80 & 10,860 \\
\hline
\end{tabular}

Linhagens utilizadas como parentais masculinos pertencentes ao grupo I: 1 = TOM-687, 2= TOM-688, 3= TOM-689 e Linhagens utilizadas como parentais femininos pertencentes ao grupo II: $1^{`}=$ TOM-690, $2^{`}=$ TOM-684.

\section{CONCLUSÕES}

As linhagens TOM-687 e TOM-688, ricas em acilaçúcares, apresentaram boa capacidade geral de combinação, podendo serem utilizadas como parentais de híbridos comerciais na geração de híbridos resistentes a pragas.

Os híbridos oriundos de linhas ricas em AA são potencialmente competitivos quando comparados às testemunhas.

Houve predominância de efeitos aditivos no controle dos caracteres avaliados, não sendo significativa a heterose específica dos cruzamentos avaliados.

\section{AGRADECIMENTOS}

À FAPEMIG, ao CNPq, à CAPES pelo auxílio financeiro e concessão de bolsas; à UFLA e à HortiAgro Sementes Ltda. pela disponibilização de infra-estrutura para a execução deste trabalho.

\section{REFERÊNCIAS BIBLIOGRÁFICAS}

ALVARENGA, M.A.R. Tomate: produção em campo, casade-vegetação e em hidroponia. Lavras: UFLA, 2004. 400p. 
AMARAL JUNIOR, A.T.; CASALIV, W.D.; CRUZ, C.D.; FINGER, F.L. Inferências genéticas na produção e qualidade de tomateiro sob cruzamento dialélico. Pesquisa Agropecuária Brasileira, Brasília, v.34, n.8, p.1407-1426, ago. 1999.

GOFFREDA, J.C.; MUTSHLER, M.A.;AVE, D.A.; TINGEY, W.M.; STEFFENS, J.C. Aphid deterrence by glucose esters in glandular trichome exudate of wild tomato, Lycopersicon pennellii. Journal of Chemical Ecology, New York, v.15, n.7, p.2135-2147, May 1989.

GONÇALVES, L.D.; MALUF, W.R.; CARDOSO, M.G; GOMES, L.A.A.; NASCIMENTO, I.R. Herança de acilaçúcares em genótipos de tomateiro provenientes de cruzamento interespecífico. Pesquisa Agropecuária Brasileira, Brasília, v.42, n.5, p.699-705, maio 2007.

GRIFFING, B. Concept of general and specific combining ability in relation to diallel crossing systems. Australian Journal of Biological Science, Victoria, v.9, n.4, p.463493, 1956.

JUVIK, J.A.; SHAPIRO, J.A.; YOUNG, T.E.;

MUTSCHLER, M.A. Acylglucose from wild tomato alters behavior and reduce growth and survival of Helicoverpa zea and Spodoptera exigua (Lepidoptera: Noctuidae). Entomology Society American, Lanham, v.87, n.2, p.482-492, Apr. 1994.

LILEDL, B.E.; LAWSON, D.M.; SHAPIRO, J.A.; WHITE, K.K.; COHEN, D.E.; CARSON, W.G.;TRUMBLE, J.T.; MUTSCHLER, M.A. Acylsugars of wild tomato Lycopersicon pennellii alters settling and reduces ovposition of Bemisia argentifolii (Homoptera: Aleyrodidae). Journal of Economic Entomology, Maryland, v.88, p.742-748, 1995.

MACIEL, G.M. Broad spectrum arthropod resistance mediated by leaf acylsugar contents in tomatoes. 2008 . 45p. Dissertação (Mestrado em Fitotecnia)-Universidade Federal de Lavras, Lavras, 2008.

MELO, P.C.T.; MIRANDA, J.E.C.; COSTA, C.P. Possibilidades e limitações do uso de híbridos $\mathrm{F}_{1}$ de tomate. Horticultura Brasileira, Brasília, v.6, n.2, p.4-6, nov. 1988.

MIRANDA FILHO, J.B.; GERALDI, I.O. An adapted model for th analysis of partial dialel crosses. Revista Brasileira de Genética, Ribeirão Preto, v.7, n.4, p.677-688, 1984.

PEREIRA, G.V.N.; MALUF, W.R.; GONÇALVES, L.D.; NASCIMENTO, I.R.; GOMES, L.A.A.; LICURSI, V. Seleção para alto teor de acilaçúcares em genótipos de tomateiro e sua relação com a resistência ao ácaro vermelho (Tetranychus evansi) e à traça (Tuta absoluta). Ciência e Agrotecnologia, Lavras, v.32, p.996-1004, 2008.

RESENDE, J.T.V.; MALUF, W.R.; CARDOSO, M.G; FARIA, M.V.; GONÇALVES, L.D.; NASCIMENTO, I.R. Resistance of tomato genotypes with high level of acylsugars to Tetranychus evansi Baker \& Pritchard. Scientia Agrícola, Piracicaba, v.65, p.31-35, 2008.

RESENDE, J.T.V.; MALUF, W.R.; CARDOSO, M.G.; GONÇALVES, L.D.; FARIA, M.V.; NASCIMENTO, I.R. Resistance of tomato genotypes to the silverleaf whitefly mediated by aciylsugars. Horticultura Brasileira, Brasilia, v.27, p.345-348, 2009.

RESENDE, J.T.V.; MALUF, W.R.; FARIA, M.V.; PFANN, A.Z.; NASCIMENTO, I.R. Acylsugars in tomato leaflets confer resistance to the South American tomato pinworm, Tuta absoluta Meyr. Scientia Agrícola, Piracicaba, p.20-25, 2006.

SAEIDI, Z.; MALLIK, B.; KULKARNI, R.S. Inheritance of glandular trichomes and two-spotted spider mite resistance in cross Lycopersicon esculentum 'Nandi' and L. pennellii 'LA2963'. Euphytica, Wageningen, p.231-238, 2007.

SILVA, V.F.; CARDOSO, M.G; MORAES, J.C.; PIMENTEL, F.A.; GONÇALVES, L.D.; NERI, D.K.P. Caracterização a avaliação de acilaçúcar sintético no comportamento da mosca-branca (Bemisia tabaci) (Gennadius, 1886) biótipo B (Hemiptera: Aleyrodidae) em tomateiro. Ciência e Agrotecnologia, Lavras, v.32, p.1408-1412, 2008. 